\title{
Marketization, Performative Environments and the Impact of Organisational Climate on Teaching Practice in Business Schools
}

\author{
Lynn Vos, University of Hertfordshire
}

Stephen Page, University of Hertfordshire

\begin{abstract}
Marketisation of higher education has emerged as a global trend in many countries and in the UK, students are now paying amongst the highest tuition fees globally. Marketisation is synonymous with performative management practices that require universities to report on an expanding range of metrics designed to demonstrate value to students and the general public. It is also changing the way educational provision is delivered and managed, including the way in which teaching practice is managed to meet the challenges of marketization, managerialism and student demand. This paper uses the concept of Organisational Climate (OC) to examine the challenges facing UK Business School academics in their teaching role in particular, focusing on the factors shaping the climate for teaching across different institutions. Using focus groups, the paper identifies the determinants of OC for teaching practice in order to explore how academics perceive their role and the effect of marketization and performative systems on the changing conceptions of teaching in higher education. The paper has wide ranging implications for business schools globally in understanding how marketisation affects teaching practice, where managerialism and metric outputs are already impacting other key agendas facing the delivery of academic subjects with a strong business orientation.
\end{abstract}

\section{Introduction}

The concept of a University education has been transformed in the post-war period to be a more accessible public good as a means to achieving a more civil society, with the aims of enriching student's minds and supporting them to acquire specific skills and attributes. However, ideological shifts in how universities are funded and managed are currently affecting teaching practice -- the activities that academics perform as knowledge seekers, creators, curators, transformers and disseminators of knowledge to stimulate inquiry and critical thinking (Collini, 2018; Trede et al., 2012). The extant literature on teaching practice can be 
grouped into four research streams (Figure 1) with the main theme linking this body of research the importance of improving teaching practice to enhance learning and student outcomes (Gibbs, 2010). To date, however, there is little discussion in the literature on how the changing ideological landscape of higher education is affecting teaching practice and its transformational role in student achievement and potential.

In the past few decades, theoretical constructs from economics (e.g. free markets) have been applied to universities to support moves to divest the state from direct subsidisation and direct involvement in higher education, despite evidence that these principles may actually distort the market for these public goods (Brown \& Carasso, 2013; Fredman \& Doughney, 2012; Molesworth et al., 2010). However, proponents argue that by removing direct government regulation, a free market or what is deemed a marketization solution will emerge to promote competition between suppliers and create more choice for consumers while also improving efficiency, transparency and quality (Molesworth et al., 2009). Marketization has in turn reshaped models of teaching and research practice to include explicit elements of "performance management and quality control of teaching and research" (Deem \& Brehony, 2005: 226, see also Deasy et al., 2016) as the means to assess whether the goals of efficiency and quality are being met.

Marketization is most visible in the growth of business education with its perceived linkages to the world of work and graduate employability and Business Schools (BS) have been the major growth sectors in most universities worldwide as the number of students has risen rapidly (see for e.g. CABS, 2019). As marketization has been accompanied by a user-pay philosophy, higher fees and an emphasis on graduate employment, students look increasingly at value for money (VFM) and how a degree prepares them for future careers (Brown \& Carasso, 2013); for many, business education appears to be the most direct route. As numbers increase, BSs have become financial 'cash cows' to cross-subsidise other university activities (McKie, 2018) and this has transformed their role. 
Although a number of key studies have examined the impact of marketization on the meaning of university education and how it affects decision-making within institutions (e.g. Brown \& Carasso, 2013; Collini, 2018; Cribb \& Gewirtz, 2013; McGettigan, 2013), there is a lacuna in relation to its impact on teaching practice and teachers in higher education (e.g.Taberner, 2018 is an exception). This paper addresses the knowledge gap on the effect of marketization on teaching practice and teachers in UK BSs. It makes a sustained contribution to the theory of teaching practice in management education, highlighting its transformative role and how marketization may impact educational theory, practice and development. The contention here is that while the quest to develop one's teaching practice has always been a challenging one, it is increasingly problematic in a higher education sector characterised by a marketized orientation with a performative approach to outcomes. A performative approach brings with it an expanding measurement regime that requires universities to report on a growing list of metrics of performance and quality, teaching quality being just one of them (Martin, 2016). A critique of how teachers perceive their work and the effect of marketization is long overdue given how crucial teaching quality is to positive student outcomes (Gibbs, 2010).

The contribution to knowledge is achieved by using Organisational Climate (OC) as a framework to understand how to theorise the changing external and internal operating environment in universities and how it is affecting academics' perceptions of their teaching role and their ability to teach effectively. Organisational Climate represents employees shared perceptions of attributes in the work environment that are deemed to affect their roles, performance, and other outcome variables such as satisfaction and productivity. (Schneider \& Rentsch, 1988). Our contribution builds on only one previous OC study that considered academics in their teaching role (Gormley \& Kennerly, 2010), however even this study has as its main focus managers, administrators and/or research active staff, and all except one study have used quantitative methodologies. Our study develops the OC area by examining the 
attributes of $\mathrm{OC}$ unique to the teaching function compared to the diverse roles undertaken by academics and adopts a qualitative approach. Using focus groups with 20 academics across a range of BSs in the UK of different sizes and missions, the study's research questions are:

- What are the main attributes of the climate for teaching practice in UK business schools?

- What are the mechanisms shaping and influencing climate attributes in UK business schools and how is this affecting the perceptions of teaching academics and their role?

Our study is of relevance to Business Schools across the world where marketization has changed the relationship between student and institution as well as how academic performance is measured. The UK however is probably a particularly good example of this phenomena not only because it is a country where marketization has arguably proceeded furthest but also because of the variations that exist between Scotland, Wales and Northern Ireland each with hybrid variations of marketization.

The paper commences with a review of the theoretical precepts of marketization and the concepts (e.g. OC) used to understand its impact. The methodology selected is reviewed alongside the conceptual framework developed followed by the results, the limitations of the study and opportunities to extend this body of knowledge through further research.

\section{Theorising the Marketization of Higher Education}

Under marketization, management practices in universities have sought to adopt the characteristics, techniques, and values of those used in the private sector. Despite the academic focus of universities as centres of learning, new practices characterized as 'performative' and the 'new managerialism' (Clarke \& Newman, 1997; Deem, 1998; Deem \& Brehony, 2005; Deasey \& Mannix-McNamara, 2016; Kalfa \& Taksa, 2017) have been used to introduce private sector business principles such as control, audit, strategic management aligned with performance targets, budget targets, business units and the generation of surpluses to maintain financial sustainability. What these principles are meant to demonstrate is "the role of 
management in efficiently allocating resources and ensuring through measurement and control systems that the goals of the organization are being pursued effectively" (Kallio et al., 2016: 686). While a new educational managerialism has arguably been introduced, its implementation is not perfect with many compromises being reached within the academy with its critical thinking ideology ${ }^{1}$. For example, according to Furedi (2010: 2), what is "particularly disturbing about the marketization of education is the attempt to recast the relationship between academics and students along the model of a service provider and customer", as derived from marketing theory on markets and value derived by consumers. This relationship is expressed through the concept of student experience (SE) to understand the value proposition in education and SE is typically measured in terms of student satisfaction, rather than what educational researchers see as more helpful measures of educational quality such as learning gain (Galbraith et al., 2012; Gibbs, 2010; Nixon et al., 2018). Questionnaire surveys are employed with students as crude measures of satisfaction that can easily be skewed by the most recent elements of memory as opposed to a deeper reflection on the totality of the educational experience (Galbraith et al., 2012; Hornstein, 2017). Operationalising the SE involves greater performance management of academics to ensure satisfaction scores meet benchmark thresholds (Deem \& Brehony, 2005). As performance in the SE is increasingly measured against metrics, time, effort as well as various strategies are employed to enhance scores, requiring a greater investment of emotional labour (Hochschild, 1983). Students are meant to be guided in their choice of institution by a proliferation of commercial rankings and league tables of the SE and other measures to inform their investment in a university education. The investment in their university education is justified through government rhetoric that they are

\footnotetext{
1 There is an interesting paradox as few people in any profession appreciate complicated evaluation schemes and so one would not expect that most educators would view increasing compliance and other requirements positively under marketization. However, the paradox for staff teaching in Business Schools is that most academic programmes in business and management emphasize the role of markets in a free and prosperous society. The opposite of marketization is a system that allows organizational actors (including both academics and administrators) untethered access to government/taxpayer resources and allows them to determine what is best without customer (student) input. Of course, promoting markets with exceptions is reasonable but in the face of growing demands for state resources for other areas of state policy means, marketization has a particular appeal if there are clear beneficiaries (the student and society) from the marketized solution.
} 
the sole beneficiaries through higher than average earnings after graduation. For universities as the suppliers, to attract demand necessitates all but the most iconic and highly sought-after prestigious institutions/courses to devote increasing resources to marketing, branding and 'customer service', all hallmarks of a competitive environment requiring institutions to achieve market differentiation by competing for customers (i.e. students). Paradoxically this shifts resources from teaching, as constrained budgets become a hallmark of marketization (Deem \& Brehony, 2005).

Martin (2016) illustrates how the new managerialism as practiced in universities may not necessarily be fully aligned to modern business practice, as companies are becoming less centralised in order to better respond to the competitive pressures of globalisation, with organisational structures made more flexible for innovation and efficiency. Universities are developing in the opposite direction however, becoming more centralised with "top-down university management, bureaucratic administrative procedures, teaching to a prescribed formula, and research driven by assessment and performance targets" (Martin, 2016: 9). Therefore, the university sector has developed its own unique forms of managerialism but has not readily embraced current private sector thinking around productivity, new technology and trends such as the challenge posed by the 4 th industrial revolution (Industry 4.0) and artificial intelligence.

\section{Approaches to marketization: The Organisation Climate (OC) construct}

Organizational climate is defined as the shared "meanings people attach to interrelated bundles of experiences they have at work" (Schneider, et al., 2013: 361). According to Schneider and Rentsch (1988), OC represents a common perceptual understanding of the working environment that can affect key organisational outcomes such as employee satisfaction, performance, productivity and organisational success. Organisational climate is shaped through employees developing a shared understanding of their environment via signals from the procedures, performance measures, directives, policies and practices of management and from 
how managers internalise and then express internal and external environmental factors through their management and leadership styles (Schneider et al., 2013; Volkwein et al., 1998). It represents "properties not of individuals but of environments" (Campbell et al., 1970: 389). As Glick (1985) argues, we need to focus on a collective understanding to help managers assess how climate is affecting outcome variables through a consensual approach rather than through a disparate and unconnected set of individual views or surveys.

OC in organisations is measured or assessed according to attributes that have meaning for employees and that are deemed to shape their environment. Ostroff (1993) has classified these attributes as affective, cognitive or instrumental, and includes such concepts as conflict, cohesion, autonomy, promotion and rewards, and bureaucracy. While the OC attributes of importance are generally unique to organisations they can differ across organisational sub-units or functional areas such as research and teaching (what Ehrhart et al. 2014 call a focussed climate) or be shared across organisations with similar objectives operating under a common set of environmental conditions (e.g. universities) (Volkwein \& Zhou, 2003). In summary, the focus of most OC studies has been to characterise an organisation or sub-unit by capturing and considering the attributes of the work environment that (a) have the most direct relevance for those involved; (b) shape the day to day perceptions of employee roles; (c) are shared through interactions in the workplace; (d) can affect outcome variables such as satisfaction and performance, and, (e) should be addressed first by management in the event of change initiatives (Ehrhart, et al., 2014; Joyce \& Slocum, 1984; Moran \& Volkwein, 1988; Schneider, 1975).

\section{OC studies and their application to universities}

OCs application to understand organisational performance has focussed largely on companies, with university related OC studies being less numerous (see for example: Lysons \& Ryder, 1989; Volkwein, et al., 1998; Volkwein \& Zhou, 2003; Allen, 2003; Thompson, 2005; Gormley \& Kennerly, 2010; McMurray \& Scott, 2013; Shulz, 2013). From the breadth of OC 
research, its application to a teaching context in universities requires recognition of the multitude of climate attributes, measures, and different organisational or individual level outcomes. Carr, Schmidt, Ford and DeShon (2003), have synthesized and classified the literature on the relationship between climate and broader outcomes. Using meta-analytic and path analysis techniques, their review of 51 OC studies identified climate attributes associated with three groups (or "facets") using Ostroff”s (1993) theoretical framework of climate attributes (affective, cognitive or instrumental) derived from social psychology. Carr et al., (2003) identified 66 attributes relevant to affective facet studies (those concerned with interpersonal or social relationships) including conflict, cohesion, involvement, participation, trust, warmth and support; 30 attributes of the cognitive facet (those concerned with professional practice), including autonomy, challenge, innovation, achievement, standards and pressure; and 34 climate attributes in the instrumental facet (those concerned with 'getting things done', Ostroff, 1993; p.61), including bureaucracy, hierarchy, management support, resource supply, rewards-promotions, intrinsic and extrinsic rewards and constraints. Carr et al. (2003) found that Ostroff's (1993) three-facet taxonomy of OC supported the proposition that OC's effect on individual level job outcomes (e.g. job performance, psychological well-being, withdrawal) occurs through its effects on cognitive and affective states of job satisfaction and organisational commitment. From the existing OC studies and the extant university studies on OC we were able to identify the main attributes to be considered in relation to teaching practice and universities from both a theoretical and behavioural perspective. These are developed in the methodology and applied to the research questions we address.

Of the research studies undertaken to date on OC in universities only one example utilised a qualitative approach (Allen, 2003) and the majority including the Allen (2003) study focus on university managers, administrators and/or research academics. Only one separated out teaching academics from managers and researchers to identify key climate attributes affecting that role (Gormerly \& Kennerly, 2010), however, the focus of the study remained 
managers and research academics. Thus, there is minimal knowledge of how the key attributes of OC shape teaching practice. The extant university OC studies have investigated climate attributes such as support, autonomy, job security, adequacy of funding and facilities, among others, either as dependent variables affected by such factors as leadership style or state regulatory environment, or as independent variables affecting such outcomes as job satisfaction, morale, performance or role stress using existing surveys developed to study the corporate sector and/or their own measurement scales

Figure 2 identifies the main climate attributes found to shape university work and working relationships in $\mathrm{OC}$ studies. The overarching theme of the previous studies is the importance of affective attributes in university climate -those that Ostroff (1993) characterised as relating to interpersonal relationships -- and how the climate attributes identified were deemed to influence them. Studies of OC in universities highlight the importance of strong interpersonal relationships, the effect of job stress or pressure, support from managers and team members, approach to management and leadership style, adequacy of facilities and funding, role conflict, ambiguity and/or job insecurity, and autonomy. Other attributes included: reward/promotion, challenge, bureaucracy, participating in decision-making and the nature and rate of change. The effect of external environments on OC such as regulation, was investigated by Shulz (2013) to outline how a market-oriented environment affected perceptions of work. As noted, only one of these studies looked at academics in their teaching role and aside from the Shulz (2013) study, marketization and its attributes have not been theorised or measured in studies of OC in universities making the area germane for investigation.

A paradoxical research challenge exists for all OC studies: the subjective and perceptual nature of the subject matter may not necessarily lend itself to the prevailing epistemologies used in the field that assume an underlying rationality in attitudes and views towards a behavioural issue. The absence of qualitative studies on OC, as Allen (2003) observed is due to 
the origins of OC research within the organisational behaviour school with its methodological links to research in gestalt psychology (a discipline whose research focus has been primarily quantitative). This has created a legacy as most OC studies "come from realist traditions and focus on measuring climate using quantitative positivistic methodologies" (Allen 2003: 64), implying that climate research would benefit from more interpretive, social constructivist approaches. Building on Allen's (2003) argument, this study uses a qualitative interpretivist approach informed by a social constructionist epistemology. The research seeks to identify the thoughts, feelings, and experiences of academics in their teaching role given a changing environment where centralised management exists, a students' as consumers perspective is promoted, and where performance measures, scores and other targets have become a significant focus of day to day operations.

\section{METHOD}

\section{Conceptual framework: Key influences}

We understand teaching practice to be the processes by which educators develop, advance, reflect on and improve their curricula, and the ways in which they interact with and assess students based on accepted definitions (e.g. Ramsden, 2013). Trigwell \& Shale (2004: 523) argue that teaching practice in university education has "core value concepts as diverse as reflection, communication, pedagogic content knowledge, scholarly activity and pedagogic research". These concepts and practices are shaped by OC but unlike the notion of service delivery and service excellence, there is no universal agreement on the approach individual academics should adopt towards teaching practice. Rather OC sets out a framework as teaching and teachers have their own unique attributes compared with other functions they undertake. Ehrhart, Schneider \& Macey (2014) differentiate between overall organisational climates (molar climates) and those related to specific functions within organisations, such as managing service delivery or health and safety (focussed climates). Following from the research on focussed climates, we consider only the teaching function and not the other 
functions that academics carry out such as research. We build on previous studies (e.g. Ehrhart et al., 2014; Lawler et al., 1974), where OC emerges and is shaped through numerous mechanisms within an organisation such as management and leadership practices. These mechanisms create shared experiences and meaning for groups or units through their interactions and discussions and these interactions can occur in different domains (e.g. as interactions between teaching academics; between academics and their managers; between academics students; and, across the academy through personal networks, conferences and events - see Allen, 2013; Gormerly \& Kennerly, 2010; Volkwein et al, 1998, 2003). From interactions within the broader academy, we see that OC can be shared not only within an institution but also across institutions when the group or groups carry out a similar role (in this case teaching). Informed by the meta-analytic research of Carr et al., (2003), we identified the main climate attributes in relation to teaching practice in universities from both a theoretical and behavioural perspective. We are also informed by Volkwein et al. (1998, 2003), Allen (2003), and Shulz (2013) who demonstrate how the external environment in universities affects OC, including Peterson and Wiesenberg (2004) who call for enhancements in the OC for teaching practice (in this case at school level) in order to ensure good outcomes for students and improved measures of teaching quality.

\section{Research Design}

This study uses a qualitative interpretivist approach, based on the assumption that a phenomenon, in this case OC for teaching practice, can only be understood through the words of those who experience it (Myers, 1997). In epistemological terms, we posit that to understand the shared or summary perception of how university teachers are affected by the OC, a qualitative approach is needed. We argue that there is an opportunity to counterbalance the existing OC literature with its quantitative instrument-based replication studies paradigm, that are not well suited to shared or summary perception research. The fundamental change embodied in marketization and its effect on the shared or summary perception requires a social 
constructivist approach to gain a deeper understanding of the data as meaning formed through the interaction with others and phenomenon in the workplace (Creswell, 2013). For this reason, a particular type of research design capable of capturing these attributes was selected based on group data capture methods within a qualitative paradigm. We selected focus groups as a suitable method which is arguably one of the most widely used qualitative research tools in the social sciences in which interaction can be encouraged, and verbal data generated for coding and content analysis (Stewart \& Shamdasani, 2014). For our study, the focus group has a great deal of merit as a method because it is suitable for exploratory studies that seek to understand phenomenological dimensions and experiential aspects within group dynamics, such as how OC is constructed and gains meaning within work environments.

Focus groups with $20 \mathrm{BS}$ academics who teach marketing were analysed to identify the perceptions, feelings, and experiences of academics about their teaching role. Building on the studies by Pettigrew (1987) and Allen (2003), the theoretical lens of contextualism was employed to look for evidence of how a changing and dynamic external environment (i.e. marketization and external and internal performance measures) shapes the working environment for teaching practice. Using theoretical thematic analysis (Braun \& Clarke, 2013), the data analysis utilised existing theoretical concepts from the OC literature to look for common themes, ideas and language emerging from the focus groups that provide evidence of how marketization is affecting teaching practice. These theoretical concepts include climate attributes shaped within different domains of social interaction in a professional context such as that between managers and employees (Poghosyan, et al., 2013; Schneider, 1970).

Potential participants were selected using the mailing list for the Academy of Marketing (AM), the learned society for marketing academics in the UK which identified 266 members from 78 UK universities. Participants were selected to include a broad range of job roles (Lecturer, Senior Lecturer, Principal Lecturer, Reader ${ }^{2}$, Professor) and tenure (from early

\footnotetext{
${ }^{2}$ Two readers were invited but did not attend so there are none in the sample.
} 
career to late career). In addition, the authors sought a proportionate number of participants from both pre-1992 universities and those that received their charter after 1992 (the 'new' universities). ${ }^{3}$ This distinction in the sampling was used because in 'new' universities custom and practice has been that staff below Reader grade have traditionally carried the burden of the teaching load and this may affect teaching practice climate.

The recruitment of participants was achieved by invitations sent to 75 potential participants by email with 22 initially agreeing to take part and 20 finally attending the focus groups on the set dates. The response rate of $26 \%$ was deemed suitable given the comparatively lower response rates now being reported for other online forms of surveys and requests for research participation (Mellahi \& Harris, 2016). As many respondents took time out of busy schedules to attend a focus group this was deemed a good outcome. Each respondent fit the criteria of being a teaching academic (most with many additional roles) representing academics at different levels of the profession and at different university types, "thus allowing for a credible representation of the entity [we] purport to study" (Macquarrie, 2009: 930). The one caveat is that the academics came from a single business discipline (marketing). Yet as marketing academics work collectively and in similar conditions to those in other business disciplines, we felt their views would be sufficiently representative for our exploratory study of the climate attributes affecting teachers in BSs.

The resulting categories of participants based on job role, institution type, tenure and gender are outlined in Table 1. As approximately $40 \%$ of UK BSs are located in the pre-1992 sector and the remainder in the 'new' university sector, the final proportion of participants in the study was deemed representative with $45 \%$ from pre-1992 institutions. The majority of participants had been in post for more than six years and there were an equal number of men and women. Focus groups were conducted by one of the researchers, who recorded the narratives which lasted between 70 and 90 minutes. All focus groups were audio-taped and

\footnotetext{
3 'New universities' is a phrase used to refer to former polytechnics that became Universities from 1992 onwards.
} 
transcribed in line with an ethnographic transcription method (i.e. a process which preserves just the words spoken rather than focusing on the intonation and language). One focus group was held in London with six participants, four of who came from different universities in the Greater London area and two from Welsh institutions. The other two focus groups, with seven participants each, met during the annual Academy of Marketing conference (a large event hosting academics from UK and international universities) and included participants from all four nations. Travel expenses were paid for those coming to the London focus group (the others already attending the conference).

Table 1 here

The focus group guideline document was developed from an original set of questions produced by the Higher Education Academy (HEA - now Advance UK) (please see Appendix 2) the main higher education teaching and learning body in the UK (heacademy.ac.uk). The guideline document originated from a study to consider how academics in various disciplines develop their teaching practice, what resources they use, how they source these resources, what additional resources are needed and how the discipline has been evolving. The questions were adapted to address the research questions in this study regarding the OC attributes that are shaping teaching practice, the significance of marketization and performative management and teachers' perceptions. The emphasis on resources was reduced and a greater emphasis placed on the factors affecting the teaching role, how participants perceived the role to be evolving, what they viewed as the main reasons for any changes arising and how they felt changes were affecting their teaching. Four main questions were constructed, and probe questions added to allow participants to broaden the discussion across a range of teaching and learning related issues should the discussion become too focussed on a particular topic (See Appendix 1). In order not to lead the respondents, no specific references were made to the concepts 'marketization' or 'performative management practices'. The question about what they saw as the reasons for changes arising was seen as an opportunity for participants to comment on 
associated marketization and performance management practices. The recordings from the interviews were transcribed and the authors undertook an initial coding exercise to establish the codes to be used to group key themes in the data in line with customary practices in focus group analysis (Stewart \& Shamdasani, 2014). These codes were then used as a basis for seeking patterns or recurring ideas that began to explain the $\mathrm{OC}$ for teaching practice and represented core OC attributes. Statements were grouped into theoretical subcategories representing evidence of $\mathrm{OC}$ attributes that are commonly cited in the literature (e.g. interaction, funding/facilities, pressure/stress, autonomy). These were then categorised into the context or domain of interaction where they appeared to occur most often. Statements from the focus groups were extracted to provide evidence of these attributes and the domain of interaction.

\section{ANALYSIS AND FINDINGS}

The first stage of the analysis of the transcribed focus groups was the identification of specific codes which were assessed by the co-authors to derive agreement on those to be used. The codes identified in the transcriptions were developed around three specific themes related to the research questions and study: $(a)$ the main attributes of OC for teaching practice in BSs; $(b)$ the main mechanisms and domain areas that are shaping and influencing $\mathrm{OC}$ attributes; and (c) evidence of the perceived impact of marketization and performative management practices.

More specifically, the attributes which characterised the OC for teaching practice were: autonomy, pressure/stress, external regulation, funding/facilities, performance/reward, interaction, diversity, epistemology, collaboration/collegiality, challenge and innovation. The coding of the transcripts around these attributes also identified four types of interactions or four domains: management, student, discipline and professional. Each domain has unique mechanisms that shape and affect different attributes of teaching practice OC and teachers' perceptions. However, there was also evidence of cross-over where various mechanisms in one domain also affect OC attributes in another, or where attributes are shaped by more than 
one domain (e.g. the greater use of part time staff). Most participants perceived that their working environment had changed considerably over the past decade and almost all the OC attributes appear to have been affected by the practices, policies and processes associated with marketization, as discussed in the literature review. This was made evident by references in the narratives to the elements of marketization discussed above such as students as customers, targets, increasing numbers of performance measures, decreased budgets, and changing management practices. The exception is innovation in the professional domain which appears to be also shaped by behavioural norms rather than a changing external environment. Each domain, their climate attributes, and how changes in the external and internal environments appear to be affecting teaching practice is now discussed.

\section{Management Domain}

The management domain represents the policies, practices, directives and budgetary decisions made by managers as interpreted by respondents. Although the precise organisational form of a specific participant's department or school varies, consensus emerged about how mechanisms in the management domain affect the teaching practice climate based on shared experiences across institutions. The findings point to the following climate attributes as being most relevant in this domain: autonomy, pressure/stress, external regulation, performance/reward and funding/facilities. Teachers in higher education have traditionally had much greater autonomy in the development of their teaching practice than those teaching at school level (Noorda, 2013), representing an individualistic culture that can present challenges to managers (Elton, 1998), and one associated with freedom of expression and curriculum design. As academics value their freedom to develop their courses, lectures, student activities and assessment, participants in the focus groups felt that greater autonomy equated with better teaching practice. This was made evident by references to 'knowing' what students should be learning, taking the initiative and being in charge of their practice. As one respondent observed: Universities [can be] stuffy institutes and we don't get funding or training ...but we are self- 
starters and do it ourselves [Senior Lecturer]. Collaborating with colleagues is not deemed to affect their autonomy except in the cases where departments rely increasingly on part-time academics to do the teaching to save money, a feature noted at many participants' universities. Planning can become difficult when part-time lecturers are only available on specific days or have limited experience in the subject area as: It's very hard to teach consistently from semester to semester when you are always getting a new VL [part time academic, no long-term contract] to teach with [Senior Lecturer].

Growing casualization and use of part-time lecturers are only two features of how participants perceive that autonomy is affected by a changing higher education environment. The need to be accountable for teaching scores on a growing range of performance metrics is another factor because it takes time away from teaching and can influence what academics choose to teach and how they assess students. For example, one new performance measure is the percentage of students from a programme that obtain graduate level jobs, and this is deemed to affect decisions about what academics teach. One outcome of these measures has been greater emphasis on developing employability skills and the need to justify how the content, assessment and delivery of a module will develop 'graduate attributes.' Employability skills are usually set out in university manuals recommending the year where skills should be developed. Numerous respondents commented that such skill requirements are important but poorly integrated within the curriculum and impact on perceived autonomy around what to teach and the time available to deliver core content. Furthermore, participants perceived that these skill requirements have grown in importance as universities are now measured against not only how many students obtain graduate employment and salaries they earn in (i.e. six months; one and three years after graduation). Confusion also remains around the differences between employability skills, graduate attributes and generic skills, all terms that appear in various guideline documents. The focus group participants argued that they needed more conversations about how and where these skills should be taught and whether they were 
helping students get good jobs. Participants found the requirements of the 'employability agenda' to be rather simplistic or too generic, challenging their autonomy in terms of what to teach, without providing evidence of their value: It is almost like deskilling or taking the thinking out and putting on a mechanistic view of delivery that is not really congruent with what employers actually want and really what we know to be what the students really need. [Principal Lecturer] and so [What we have is a] lumpen curriculum; a grinding down of the curriculum so it is 'employable', so it has 'managerial relevance' and ultimately not theoretical. [Professor].

Respondents also observed that there was pressure not to make changes to the curriculum within five-year review cycles, with each change having to be justified and vetted. This has been accelerated by a new consumer law from the UK Competition and Markets Authority (CMA) about universities legal obligations. What is in print must be delivered and universities must "give students clear, accurate and timely information" about what is in the programmes and modules they study (CMA, 2015). The intention here is that the SE should map exactly to what they experience in situ as reflected in the following quotation: There is so much paperwork involved with just making any small change to our module...we have to make those changes at least a year in advance if they are to be approved and meet regulations. How can we stay up to date in our curriculum? [Senior Lecturer]. Autonomy is also affected by other OC attributes shaped by the management domain - pressure/stress, promotion/reward and resources. Pressure and stress were dominant themes in the focus groups and all academics felt pressure to carry out more and more varied functions under current budget and management conditions. In addition to teaching and research, most respondents have an administrative role, with some also engaging in consultancy, community projects or overseas programmes at international campuses. The pressure induced by an ever-expanding set of expectations in their roles and responsibilities is deemed to significantly affect the time and effort that academics can devote to developing their teaching. This is seen as incongruous to many participants given 
the growing internal and external metrics of teaching quality as measured by such tools as the National Student Survey (NSS) (The US and Australia use the National Survey of Student Engagement), the UK Engagement Survey, the UK Student Academic Experience Survey and now included in the Teaching Excellence Framework, a new set of processes and outcomes that universities must report on (See Appendix 2 for a brief overview of these measures).

Several of the universities represented in the focus groups had recently undergone restructuring and this created a perception among academics that higher workloads tended to follow restructuring as resources and funding were increasingly stretched, epitomised by: We have gone through three restructurings of the School in four years - it's very hard to keep up but one thing is for sure, we seem to have smaller budgets, and fewer part-time staff members each time and more responsibilities [Principal Lecturer]. While another respondent argued that: We [as academics] seem to be taking ownership of a great deal of responsibility...Our managers don't seem to be managing, our departments don't seem to be doing what they are supposed to and yet we have excellent colleagues who deliver against all the odds....Perhaps the HEA [See Appendix 2] could be helping us get the message across to our managers that we want to be good teachers, but we face so many pressures, we have so many responsibilities [Professor] reinforced by a respondent who stated that: We have so many roles to carry out these days, it feels like marmalade being spread ever more thinly across an expanding pie [Senior Lecturer].

The managerial requirements to be effective across many roles and to constantly measure outcomes are also perceived to affect performance and reward, particularly promotion prospects. Participants perceived that it is more difficult now to get promoted than in the past and that job role descriptions are expanding, particularly if academics are not at the professorial level as evidenced in: It seems to me that every time I want to apply for promotion, the criteria seem to have expanded. It used to be much easier to become a principal lecturer [Senior Lecturer]. Commenting on promotions, those from more research-intensive institutions noted 
that little value is placed on teaching excellence or innovation when it comes to appraisals or promotions and thus, they cannot justify spending too much time on teaching-related matters. Their priorities are to publish in top ranked journals to meet the government research evaluation exercise (The Research Excellence Framework, REF - See Appendix 2) as reflected in: I was wondering why I don't do more to develop my pedagogy - and I guess the reason is that I have to prioritise my time - and research wins every time. Since I am generally considered a decent tutor by students, I don't feel under pressure to improve my pedagogy, but I do feel under pressure to increase my research outputs [Professor]. Even though professors are less affected by promotion rounds, they too spoke about increasing expectations to take on more $\mathrm{PhD}$ candidates, teaching, supervision and/or committee work.

The requirement to achieve high scores on internal and external metrics also puts pressure on academics. Those with current or prior programme lead/chair responsibilities felt pressure to achieve good scores on internal programme and module surveys, the NSS, on student retention and on graduate employment figures, even though they perceived having limited control over the outcomes on any measure. Those with more research-oriented roles were less affected by results on student satisfaction surveys such as the NSS, but stress was evident: The NSS affects league table positions but I think research does more so...the REF puts a great deal of stress on us as does the requirement to publish in [high ranked] journals [Professor]. Meeting targets also meant that those in leadership roles spent a great deal of time writing reports about achieving or not achieving various targets and suggesting plans for improvement. A participant who was also a subject lead (quasi-department head/chair) commented that each year they wrote similar recommendations, but these were rarely read: $I$ spend a lot of time completing documents that never get read like the annual monitoring report and a management report on module feedback in the group, but I have to do that in my role, regardless [Principal Lecturer]. The commentary on how uncomfortable academics feel that their teaching and learning practice is not "up-to-date" appears to be a manifestation of this 
stress. In fact, participants concurred that there was less funding available to develop their teaching materials, to attend external industry or teaching and learning events and that managers had other priorities for funds. The consequence, as observed by some participants, was that they used their own money to attend or to purchase teaching resources no longer available at their university and, even though deemed unfair, many will continue to do so to keep their knowledge up-to-date. While most use freely available desk copies of subject textbooks, the media, industry publications and academic journal articles in developing their curriculum, participants found it difficult to get extra money for teaching resources not carried in their libraries such as relevant books, videos and case studies. While libraries were viewed as good in most cases, they were perceived as spending less on books (still an important resource for undergraduates), while at the same time UK students are increasingly reluctant to buy core textbooks. Respondents noted that resulted in many students coming to class not having read the required material or that they had to use older versions of the textbook available in the library.

Other resource-related factors related to technology and timetabling also emerged. When a participant who had been teaching for twenty-five years noted that they felt the main drivers of their work is the university estates and technology teams, many agreed they faced similar issues. Problems with technology, teaching rooms and timetabling all placed constraints on teaching practice by eating into the time available with students, creating an uncomfortable learning environment, and/or affecting student attendance as: I feel that the estates team at the university has the greatest impact on my teaching - technology not working, rooms too big or small or cold or hot, a timetable that's all over the place [Professor]. While another respondent stated: How many times have I walked in to give a lecture or seminar and the technology doesn't work? Innumerable and frustrating [Lecturer]. Some respondents commented that managers were not prioritising facilities or resources such as additional teaching staff while others saw it as university-level budgetary restraint in a time when predicting the number of 
applicants is increasingly difficult. For institutions that are taking in more students since the government removed recruitment caps (2015) in order to make the sector more competitive, larger classes are becoming the norm, but facilities have often not caught up despite the millions of pounds being invested in other parts of the estate.

\section{Student Domain}

The narratives pointed to interaction and diversity as the main OC attributes discussed by academics in their relationships with students. Respondents discussed a changing student body, using the metaphor of 'students as customers' in their discussions of academic/student interaction. While there was no consensus as to what it meant in practice, phrases such as "reconfiguring the role of the student", "focussed mainly on grades and jobs", "a more instrumental" or a "more transactional student" came up in the conversations. For example: Market forces have reconfigured the role of the student. Students... think of themselves as customers and the great arguments [in our profession] are now in that interface between student versus customer [Professor] and Students are more instrumental these days - they just want to know what they have to do to get a good grade...they are so focused on grades because they want to get a good job when they graduate [Senior Lecturer]. There was consensus that students should have a strong voice in higher education, but trepidation by some in using the producer-consumer framework, language associated with the marketplace, to characterise the academic-student relationship. The argument put forward was that it misrepresents the shared value and co-creation that occurs during the student's learning journey. Nevertheless, given that the respondents were marketing academics, an extended discussion occurred about the meanings of value inherent in different forms of exchange.

The focus groups noted that the interaction between students and academics - at least at the group level - is decreasing because attendance is dropping at lectures and seminars, for reasons not entirely understood. While some respondents saw this as a trend related to students using recorded lectures and needing to work because of educational debt, others felt that 
students want and need more interaction, particularly one-on-one: I don't think students want remote access...they want personal access... and when they are put in large rooms, they are disappointed, and I think they want more personal contact time, more one on one or small group time together. If you asked them, nearly all would say they want more contact time [Senior Lecturer]. Comments were made about decreasing contact hours per programme, generally perceived as a means to save resources, and time pressures on academics, particularly those with large cohorts which made more one to one time difficult. Most academics felt that meeting students individually helped motivate them and build their confidence and achievement. However, the quality of interactions with students was perceived to be weak in cases where students did not come prepared, a feature observed in relation to major projects and dissertations, and routinely for seminar activities.

In terms of the changing student body, the government-mandated widening participation agenda is creating a more diverse group of students at many institutions (Shaw, 2009). The drive to attract higher fee-paying students (international and postgraduate) to generate income was a common theme in the discussions. Interestingly, almost all institutions represented in the focus groups drew upon a common pool of students for postgraduate education. In other words, academics noted that regardless of their university type and ranking in the league tables, students with lower overall grades in their undergraduate degrees, often between $50-59 \%$ and sometimes those with $40-49 \%$ were now being admitted to their master's programmes: All respondents agreed that master's applicants with English as a second language had linguistic challenges hindering their learning, often resulting in lower grades compared with home students and work that often did not equate to master's level. While widening participation is deemed necessary and valuable to the overall educational experience of all students and for universities social objectives, it is also perceived to lead to much greater diversity in terms of students' skills, motivations and prior education. Weaknesses in students' numeracy, analytical and critical thinking skills were discussed in all focus groups as: My students have such a 
range of skills and skill-deficits - numeracy, being able to write well and of course about $75 \%$ our postgraduate students are from overseas and English is not their first language [Senior Lecturer].

Among the different perspectives on the outcomes of growing diversity were that international students who make up the main cohort of most master's programmes in marketing (80\% or more in most cases) come from different educational backgrounds where a questioning or critical approach to knowledge is not fostered. A one-year masters is just too short for such students to come to grapple with both the linguistic and critical thinking challenges. For home students, other problems identified included prior learning in UK schools where the focus is on 'passing the test' rather than on developing thinking skills; students who do not read very much either within or outside university; lack of student engagement; and, large lectures requiring more didactic approaches that do not encourage critical thinking. Respondents agreed that teaching students to think critically is a key role of a university educator and yet they feel frustrated in their ability to achieve this outcome because of student skill weaknesses, language problems or apathy.

How do the student-related factors affect teaching practice? Respondents conveyed a sense of frustration through phrases such as they "aren't really understanding what I am talking about a lot of the time (regarding postgraduate dissertation students)", "I changed my assessment"; "I used simpler language"; "marking is often demoralising"; "tend not to use as much theory as I would like"; and "students can't do numbers even though marketers use numbers daily." The conversations about student-related effects on teaching practice were also peppered with references to the many metrics that universities are measured by, including the NSS ("we must keep students happy"; "poor measure of what they have learned"), league tables ("we should get stronger students given our league table position"; "we are very low in the league tables so we get weaker students"), retention ("no matter how weak the students are, we need to keep them to keep getting the government grant") and value-added requirements 
(remarks about grade inflation). In two focus groups, a short discussion emerged about pressure to keep marks up regardless of students' actual performance, given that grades are published nationally. Despite the pessimistic comments, it was clear that academics like teaching, enjoy the interactions with students and find it one of the more fulfilling aspects of their overall role. However, there are many frustrations related to the changing environment for higher education.

\section{Discipline Domain}

A pronounced tension that emerged in the discussions was epistemological and common to professional subjects. Marketing educators struggle with how to balance the curriculum between teaching students how to 'do' marketing and teaching 'about' marketing, including its theoretical and historical underpinnings (e.g. Schibrowsky, et al., 2002). The tension arises in terms of how to balance time and resources to develop future marketing managers versus educating students more broadly (i.e. focusing on ethics, critical thinking and writing). Participants in all focus groups identified the main factors affecting their teaching role, noting that managers, employers and students - and even some colleagues - felt that marketing should be about the "how to" of marketing particularly where the discourse emphasises employment as a key outcome of university education. Critics viewed this as reducing the subject to a training regime without the critical, historical and theoretical underpinnings that a university education should offer as illustrated thus:

The struggle for the soul of marketing education goes to the heart of the issue....we could all talk for one hour on what marketing is.... a simple dichotomy...marketing that is complex and sophisticated and marketing that is simple and obvious.....and we would move in the direction of deep learning, criticality and a degree of sophistication in thinking....macromarketing and society...but .......Most of the time, most business people think of marketing as selling and most of our managers and many of our colleagues, think that it is about getting jobs and that is what we should be teaching [Professor].

\section{Professional Domain}


The professional domain represents the opportunities, policies and requirements set out by managers, industry associations, and educational accrediting bodies for academics to develop and upgrade their teaching practice and to gain certification or accreditation (Hampton et al., 2009). It includes a set of behavioural norms that shape how employees think about their profession and the role of training (Cullen, 1978; Hampton et al., 2009; Wilensky, 1964). The OC attributes arising from the focus groups associated with the professional domain are funding/facilities, challenge, innovation and collaboration. Since 2011, UK universities have had to publish the teaching qualifications of their academic staff (White Paper, 2011). This has resulted in pressures to acquire teaching qualifications which were not, for many, a prerequisite to joining the Academy. Teaching qualifications are a contentious issue but all focus group members, except for one professor, had accreditation through the HEA (the main UK body that awards accreditation). All academics are required to take up continued professional development and, in some cases, promotion is linked to the amount and type of training acquired. In terms of teaching practice, professional development involves activities undertaken to update knowledge in the subject area as well as in pedagogy (i.e. the theory and practice associated with improving learning, see Waring, 2014). From the narratives it was evident that this aspect of their work can represent a welcome and enjoyable challenge, particularly the drive to stay abreast of theoretical and practical developments in the subject area for both research and teaching purposes. Not surprisingly given the earlier discussions of department funding, funding/facilities as an $\mathrm{OC}$ attribute emerged in the professional domain. Many participants felt the most effective way to learn and share ideas about teaching and learning is through personal conversations with colleagues both informally and at events and conferences. Yet little money was made available for attending teaching-related conferences because they are not deemed as important as research-related events: Our university only allows us to go to a conference if we are presenting a paper that we will then write up for publication - my area is services marketing, so I can't go to an external teaching and learning 
conference - I go to the internal one each year though [Lecturer]. Collaboration in teaching practice was highly valued in developing subject knowledge, teaching content and pedagogy:

One of the most valuable things about the Academy of Marketing (AM) conference is learning about teaching marketing...just being in a community of marketing educators, having the opportunity to share practice. I learn so much from the AM conference and build my network. I have some really good friends from there and I always come back from the conference really invigorated and excited with new ideas for my teaching and research [Senior Lecturer]. and

HEA [Higher Education Academy] and AM don't need to give us the content, but find ways for us to learn from each other, you know, collaboration, co-creation...that will hopefully continue after the event [Principal Lecturer].

In terms of innovation in pedagogy, the narratives demonstrate a different perspective. There was a common perception that marketing academics are not as familiar with or skilled in the kinds of technologies used for different forms of teaching and marketing practice and this appeared to be a concern: ...teaching in the subject will require academics to be more adept with the technology used in marketing and the techniques of effective distance and online learning. Most don't feel they currently have these skills [Lecturer]. No discussion emerged in any focus group as to how this knowledge and skill gap could be bridged. While all of those participating in the focus groups have attended teaching and learning conferences, generally held annually at their own institutions as a source of ideas and to share practice, few academics had recently attended free HEA teaching events; the low turnouts suggested time pressures, but also ambivalence: Although there are many free events put on by the HEA neither I nor my colleagues attend them...so having more such events probably wouldn't make a difference [Senior Lecturer]. Given that so few academics attend external pedagogy-related events, exposure to a wide range of ideas and research is constrained; thus, innovation in pedagogy was lagging in their list of priorities as a few respondents spoke about discipline specific or more generic journals of higher education:

Being familiar with the academic literature pertaining to marketing education is helpful since there are so many descriptions of practices that have been tried out, and evaluations 
of methods that work well, or not so well...Articles that have been most helpful over the years have [been about] managing group work, using case studies [and] simulation games in marketing education...the broader literature on experiential methods of learning...[Professor].

While most were familiar with pedagogic resources such as the Journal of Marketing Education, they made little or no use of these. New ideas tended to come from discussions with others directly or from online discussion platforms rather than from more formal evidencebased sources. This lack of engagement with the literature on the theory and practice of teaching and learning may be characterised as an academic-practitioner divide where the teacher in this case is the practitioner who is not, for whatever reason, engaging with the academic literature on pedagogy.

\section{DISCUSSION}

The OC for teaching practice for marketing academics appears to meet the requirements of a focused OC as identified by Ehrhart, Schneider and Macey (2014) because it represents a subset of employees within the university working on a related function - teaching. In analysing the narratives, a number of mechanisms appear to be shaping teaching practice OC in UK BSs, many of which are affected by a marketizing higher education environment (i.e. a growing number of internal and external performance measures and performance targets; competition for students; squeezed budgets, greater management scrutiny, among others). Furthermore, this OC is shared across institutions because all respondents were affected by similar trends as well as performance targets and because the role carries similar responsibilities and expectations. Few differences emerged between institutions or between roles. Teaching practice $\mathrm{OC}$ is shaped and experienced within four domains - management, student, discipline and professional, and is characterised by the following attributes: autonomy, pressure/stress, external regulation, promotion and reward, funding/facilities, interaction, diversity, epistemology, challenge, innovation and collaboration. This study has found 
diversity and epistemology to be attributes of the OC for business school academics, attributes not identified in previous studies of university climate (Allen, 2003; Lyson \& Ryder, 1989; McMurray \& Scott, 2013; Volkwein \& Zhou, 2003). All but two climate attributes, challenge and collaboration appear to be creating perceptions of a role that is increasingly difficult to perform satisfactorily. According to participants in the focus groups, ideal conditions for teaching practice development would include the elements outlined in Figure 3. No academic in this study expects that all of these preferences could be met in the current environment for higher education, but we can view Figure 3 as a set of benchmarks to be addressed in improving the OC for teaching practice, since the evidence shows that they are all in need of improvement.

Figure 3

Despite the numerous concerns discussed, respondents universally enjoyed the challenge of developing their courses and working with students. The notion of not being satisfied with working conditions but still loving the job they do was demonstrated by Boyer, Altbach and Whitelaw (1994) who found that faculty are rarely satisfied with their institutions and working conditions; but if they had to choose academia again as a career would quite eagerly do so. Nonetheless, since the Boyer et al. (1994) study was conducted, universities have come under pressure to do more with fewer resources and full-time academics are taking on more roles than before, creating higher levels of stress. As Stevenson et al. (2014) found, many academics are being stretched to be highly effective as teachers as well as in research and service roles, but this stretch means they rarely feel they are doing well across any or all roles. Other studies support the idea that stress and role conflict arising from the need to carry out so many different functions affect academic satisfaction and performance (Bolden et al., 2014; Hagedorn, 2000; Kolsaker, 2008; Shulz 2013). A factor that both mediates stress and contributes to greater academic job satisfaction and is found to be an important OC attribute in this and other studies, is collaboration combined with positive relationships. Hagedorn (1994) 
found that reducing stress (unsurprisingly) has a positive influence on job satisfaction and more frequent and positive personal interactions between academics and between academics and managers is particularly helpful. These findings represent an opportunity for managers to improve the $\mathrm{OC}$ for teaching practice without significant extra resources. Prior research has also shown that academics may experience less stress if they have control over their work and have opportunities to grow and develop (Fredman \& Doughney, 2014). Participants in this study voiced concerns about autonomy and promotion and reward mechanisms that are increasingly difficult to obtain, thus contributing to stress. Despite the government's moves to raise the value of teaching in relation to research in the UK, it is perceived as having less status and fewer opportunities for advancement, so those who wish to move up the academic ladder must prioritise research, often, in their view, at the expense of time devoted to teaching (see also Stevenson et al., 2014). Paradoxically, as noted above, this is occurring at a time when universities need to report on an increasing number of measures of teaching quality and when teaching-related income is the main source of funding for most universities.

Managerialism and its effect on teaching practice are evident in the OC attributes of external regulation, autonomy, diversity and promotion and reward. Characteristics of managerialism include a marketized external environment made up of stakeholders who control resource allocation and quality rankings, a more hierarchical and bureaucratic internal management designed to respond to these conditions and more measures of performance and outcomes (Deem, 1998, Deem \& Brehony, 2005). To ensure the institution remains viable and competitive, managers feel the need to restructure, reorganize, and exert more control over academics' work through "a battery of mechanisms of audit and control” (Kolsaker, 2008: 516). These mechanisms are viewed as reducing academic autonomy, or as Kolsaker (2008) notes, "the self-management and self-direction" (Kolsaker, 2008: 156) that was once a greater feature of the academic's job. Accompanying a more market-oriented environment with higher student fees are quality assurance mechanisms meant to demonstrate that the education 
provided is good value for money (Burgess et al., 2017). Associated with this, continued institutional pursuits of annual efficiency gains (Deem, 1998) has meant a general perceived reduction in the pool of funding available for teaching practice development. Respondents in this study commented that the current higher education environment means the requirement to perform well on so many external and internal metrics of value and quality means less time and other resources available to develop their practice and that these requirements also reduce autonomy. While respondents appear resigned to this increasingly metrics driven environment, they express frustration over the lack of control they have over the outcomes of these measures and their seeming arbitrariness as measures of student learning and teaching quality. Students who assess academic teaching practice through course questionnaires and the NSS appear to be more narrowly focused than ever on two aspects of the entire educational experience - grades and jobs. It is likely that this focus is influenced by their obligation to pay off ever-higher debts, to say nothing of the diminishing confidence they feel that their degrees will ensure satisfactory employment. Klinger and Murray (2012) observed that having students with a greater range of skills and skill deficits, who are more exclusively focused on the materially self-interested side of their education can reduce the satisfaction that academics gain from their interaction with students. At the very least, the narratives in this study strongly suggest that the relationship between teacher and student is being reconfigured, but the outcome in terms of teaching practice and student learning remains. The challenges associated with balancing the curriculum in a professional discipline taught in BSs has wide ranging implications for the OC for teaching practice that have not been discussed in previous studies. Within the disciplinary literature across subjects in BSs such as marketing, there are different schools of thought on what the curriculum should focus on. Given that marketing like many BS disciplines have become more complex with the impact of globalisation and the digital age, many researchers call for curricula that is more applied and attuned to the needs of practitioners (e.g. Hulbert \& Harrigan, 2012; Koch, 2013). Other studies have highlighted the internal challenges facing 
many BSs, as Catteral, McLauren and Stevens (2002) epitomise, where the curriculum should be rich in theoretical and critical perspectives and not only a "technocratic focus that emphasizes the 'what' and 'how to' of marketing management, [a focus that actually] fails to meet the needs of managers who work in the increasingly uncertain and complex world of marketing practice" (p. 186). Their reasoning is that the modern marketing and management environment is far more challenging than that engendered by new technologies and that students need the skills and aptitudes to manage change, to solve difficult problems, to think cross-functionally, to reason critically and to make sound judgments. Designing a curriculum that develops these higher-level skills requires education in critical thinking in addition to ensuring job ready graduates and this is extremely difficult in a three (or four -Scotland) year undergraduate degree with pressure to reduce contact hours; thus it represents a significant challenge that shapes the climate for teaching practice.

In terms of professionalism, innovation and developing one's own teaching practice, the narratives produced a mixed set of messages. Despite the pressure on the curriculum, participants expressed great satisfaction in developing and keeping their teaching content up to date and show willingness to spend their own money to attend events and purchase relevant resources in an environment of stretched departmental budgets. They saw collaboration, particularly informal discussions with colleagues at internal and external events as the key to developing subject knowledge and pedagogy. But with respect to pedagogy, very few have engaged with the vast higher education literature on evidence-based practices or attended a pedagogy-based event that could improve or enhance their teaching techniques and practices within a more diverse and higher-student staff ratio context, even when such events are free. Very little discussion could be found in the literature to help explain this and it should be a focus of future research. Wilensky (1964) and Cullen (1978) have discussed behavioural norms developing around continuing professional development (CPD) that are often driven by management priorities. Perhaps this lack of engagement with the pedagogic literature is not 
only an issue for teachers but a broader institutional one. In their review of institutional marketing materials and their interviews with 33 senior managers at 11 universities of varying rank and size, Stevenson et al., (2014) found almost no references were made to the pedagogy that underpinned an institution's approach to teaching quality or excellence; instead, quality and excellence were defined with reference to league table positions, NSS scores and other metrics - the current priorities in a marketized environment.

\section{CONCLUSION}

This study of OC in a university setting has identified a range of factors affecting teaching practice, particularly the shift towards a more performative and marketized higher education sector. Critics of these changes have pointed to the role of the university teacher now being required to add a new strand to their delivery - edutainment to delight their customers, which is associated with content with a teaching focus that is also intended to have entertainment value to create 'satisfied customers' in a marketized system where the customer is theoretically speaking - always right. The central tenet of marketization is the performance to a service blueprint for educational delivery to meet various performance measures (e.g. the NSS and TEF) and student outcomes such as graduate employment. The state introduction of reductionist research tools such as the NSS are nevertheless perceived by policymakers to have been effective in the commercial world, contributing to value creation and in driving up profitability through enhanced satisfaction and they should do the same in higher education. The entire area of satisfaction ratings remains a contested theme in education settings (often as the participants have no depth of understanding of what they are being asked to score - see for example Hornstein, 2017) where institutional rankings encourage increased competition through the intended outcome of improved satisfaction scores. Our findings indicate that this marketization culture is directly impacting upon the willingness and ability of educators to develop their teaching practice and to take risks in terms of innovation in teaching. Without such innovation in teaching practice, it is unlikely that the kinds of transformative educational 
experiences needed to prepare students for the increasingly complex world they are entering will be missing. The risks with innovation in teaching practice and the effect on performance measures if they do not work in the way envisaged may even jeopardise staff careers and employment prospects in extreme circumstances where low scores are mistakenly judged as poor performance. Thus, a standardised model of delivery is often the default position which paradoxically students will also rate as average as it is not innovative or entertaining.

It is clear that the findings in this study are limited by the small sample and by the research approach and so it is exploratory in nature. Yet it has sought to develop a deeper meaning and understanding of the issues in contrast to many of the performance measures used in a marketized educational setting where quantitative measures are used to measure experiential issues. We recognised that the use of focus groups as a research tool can limit the expression of individual differences; however, since the objective of OC research is to assess the common experiences of people within a work environment and find what is relevant and shared by many, focus groups do have a critical role to perform in exploratory studies such as this. The participants in the focus groups came from a geographically diverse set of institutions representing the breadth of missions, objectives and league table positions in the UK, supporting our argument that a representative series of experiences were sought. However, the sample remains small and further research is needed to assess whether the views expressed are generally representative of academics in other BS disciplines. The narratives have identified OC features found in other studies but have also highlighted two others - diversity in the student cohort and epistemology that have not been identified previously. Both appear to be of growing concern to marketing academics and further research is needed to clarify the dimensions of these OC features and their impact on teaching practice. Apart from Shulz's (2013) quantitative study, this is only study to have considered how marketization is impacting university OCs, and with the availability of resources a larger study involving academics would also help to further develop our understanding of what attributes are having the greatest effect 
on teaching practice. Educators seek to provide students with the tools and capabilities to be successful in their careers, to become valuable members of their communities and to develop the skills for lifelong learning. A marketized model that seeks to increase participation in higher education and to meet the challenges of a civil society (Edwards, 2013) and economy, embodied in the recent UK Government Industrial Strategy (HM Government 2017) will require innovations in teaching practice as societal needs change. For example, the challenge posed by the 4th industrial revolution (Industry 4.0) and digitization are critical to the graduate employability agenda and needs of a future workforce. The teaching practices of universities, particularly the BSs, perceived as preparing graduates for business and work, need to demonstrate new and challenging ways to think and work through innovative teaching practices. These approaches may be experimental and not necessarily endorsed through student assessment of their success in surveys such as NSS in early iterations. Their cumulative benefit through time may only be discovered at a later point when students are in work. The simple cause and effect reductionist measures of NSS do little to create a safe environment for teaching innovation, meaning we need to remove any repercussions for experimental curricula that seek to stretch the intellect and create challenges that are real and akin to the world of work. Our findings demonstrate that the implications of not fostering innovation in teaching practice could lead to external stakeholders deeming BSs as not fit for purpose in the graduates they prepare if they have little intellectual value added throughout their university journey by failing to innovate in teaching practice.

\section{References}

Academy of Marketing (https://www.academyofmarketing.org).

Allen, D.K. 2003. Organisational climate and strategic change in higher education: Organisational insecurity. Higher Education, 46(1): 61-2.

Biggs, J.B. 1996. Assessing learning quality: Reconciling institutional, staff and educational demands, Assessment and Evaluation in Higher Education, 21(3-15): 5-15. 
Bolden, R., Gosling, J., \& O'Brien, A. 2014. Citizens of the academic community? A society perspective on leadership in UK higher education. Studies in Higher Education, 39(5): 754770.

Boyer, E.L., Altback, P.G., \& Whitelaw, M.J. 1994. The academic profession: An International Perspective. Princeton, N.J.: Carnegie Foundation for the Advancement of Teaching.

Brown, R., \& Carasso, H. 2013. Everything for Sale? The Marketization of UK Higher Education. London: Routledge.

Burgess, A., Senior, C., \& Moores, E. 2017. A 10-year case study on the changing determinants of university student satisfaction in the UK. PLoS ONE, 13(2): 1-15. Available at: doi.org/10.1371/journal.pone.0192976.

Campbell, J. P., Dunnette, M. D., Lawler, E. E., III, \& Weick, K. E. 1970. Managerial behavior, performance, and effectiveness. New York: McGraw-Hill.

Carr, J. Z., Schmidt, A.M., Ford, J. K., \& DeShon, R. P. 2003. Climate perceptions matter: A meta-analytic path analysis relating molar climate, cognitive and affective states and individual level work outcomes. Journal of Applied Psychology, 88(4): 605-619.

Catterall, M., Maclaran, P., \& Stevens, L. 2002. Critical reflection in the marketing curriculum. Journal of Marketing Education, 24(3): 184-192.

Chartered Association of Business Schools (CABS). 2019. The changing shape of business education provision. London: CABS. Available at: https://charteredabs.org/wpcontent/uploads/2019/03/CABS41233_2019_Future-Trends-Report_WEB.pdf [Accessed $3 / 6 / 2019)$

Clarke, J., \& Newman, J. 1997. The managerial state: power, politics and ideology in the remaking of social welfare. London: Sage.

Cribb, A., \& Gewirtz, S. 2013. The hollowed-out university? A critical analysis of changing institutional and academic norms in UK higher education, Discourse: Studies in the Cultural Politics of Education, 34:3, 338-350.

Collini, S. 2018. Speaking of universities. London: Verso Books

Competition and Markets Authority, UK

https://www.gov.uk/government/organisations/competition-and-markets-authority. [Accessed 27. 11.2018].

Cullen, J.B. 1978. The Structure of Professionalism: a quantitative examination. New York: Petrocelli Books.

Deasy, C., \& Mannix-McNamara, P. 2016. Challenging performativity in higher education: Promoting a healthier learning culture. Global Voices in Higher Education. Available at: DOI: 10.5772/intechopen.68736. [Accessed 15.05.2018]. 
Deem, R. 1998. New managerialism and higher education. The management of performances and cultures in universities in the United Kingdom. International Studies in Sociology in Education, 8(1): 47-70.

Deem, R., \& Brehony, K.J. 2005. Management as ideology: The case of "new managerialism" in higher education. Oxford Review of Education, 31(2): 217-235.

Department for Business, Energy and Industrial Strategy, 2017. Building our Industrial Strategy: Green Paper. https://www.gov.uk/government/consultations/building-our-industrialstrategy. [Accessed 27.11.2018].

Department for Business Innovation and Skills, 2011. Students at the heart of the system: White Paper. https://www.gov.uk/government/consultations/higher-education-white-paperstudents-at-the-heart-of-the-system. [Accessed 10.03.2019].

Dunkin, M. J., \& Precians, R. P. 1992. Award-winning university teachers' concepts of teaching. Higher Education, 24(4): 483-502.

Edwards, M., Ed., 2013. The Oxford Handbook of Civil Society. Oxford: Oxford University Press.

Ehrhart, M.G., Schneider, B., \& Macey, W.H. 2014. Organizational climate and culture: An introduction to theory, research and practice. London: Routledge.

Elton, L. 1998. Dimensions of excellence in University teaching. The International Journal for Academic Development, 3(1): 3-11.

Entwistle, N. 1998. Motivation and approaches to learning: Motivating and conceptions of teaching. In S. Brown, G. Thompson, \& S. Armstrong (Eds.), Motivating Students (pp. 15-24). London: Kogan Page.

Fives, H., \& Gill, M.G. (Eds). 2015. International Handbook of Research on Teachers' Beliefs. New York: Routledge.

Furedi, F. 2010. Introduction to the marketization of higher education and the student as consumer, p.1-9, in Molesworth, M., Scullion, R., \& Nixon, E. (eds) The Marketization of Higher Education, London: Routledge.

Fredman, N., \& Doughney, J. 2012. Academic dissatisfaction, managerial change and neoliberalism. Higher Education, 64(1): 41-58.

Galbraith, G.S., Merrill, G.B., \& Kline, D.M. (2012) Are student evaluations of teaching effectiveness valid for measuring student learning outcomes in business related classes? A neural network and Bayesian analyses, Research in Higher Education, 53(3): 353-374.

Gibbs, G. 2010. Dimensions of quality. York: Higher Education Academy.

Glick, W. H. 1985. Conceptualizing and measuring organizational and psychological climate: Pitfalls of multilevel research. Academy of Management Review, 10: 601-610.

Gormley, D., \& Kennerly, S. 2010. Influence of work role and perceptions of climate on faculty organisational commitment. Journal of Professional Nursing, 26(2): 108-115. 
Hagedorn, L.S. 1994. Retirement's proximity role in the prediction of satisfaction in academe. Research in Higher Education, 35(6): 711-728.

Hagedorn, L.S. 2000. Conceptualizing faculty job satisfaction: Components, theories, and outcomes. New Directions for Institutional Research, 105: 5-21.

Hativa, N., Barak, R., \& Simhi, E. 2001. Exemplary university teachers: Knowledge and beliefs regarding effective teaching dimensions and strategies. Journal of Higher Education, 72(6): 699-729.

Henkel, M. 1997. Academic values and the university as corporate enterprise. Higher Education Quarterly, 51(2): 134-143.

Higher Education Academy, www.heacademy.ac.uk [Accessed 12.03.2019].

Hochschild, A. R. 1983. The Managed Heart: Commercialization of Human Feeling. Los Angeles: University of California Press.

Hornstein, H.A. 2017. Student evaluations of teaching are an inadequate assessment tool for evaluating faculty performance. Cogent Education, 4(1). Available at: DOI:

$\underline{10.1080 / 2331186 X .2017 .1304016}$

Hulbert, B., \& Harrigan, P. 2011. How can marketing academics serve marketing practice? The new marketing DNA as a model for marketing education. Journal of Marketing Education, 33(3): 253-272.

Joyce, W. F., \& Slocum, J. W. 1984. Collective climate: Agreement as a basis for defining aggregate climate in organizations. Academy of Management Journal, 27: 721-742.

Kalfa, S., \& Taksa, L. 2017. Employability, managerialism and performativity in higher education: a relational perspective. Higher Education, 74(4): 687-699.

Kreber, C. 2000. How university teaching award winners conceptualise academic work: Some further thoughts on the meaning of scholarship. Teaching in Higher Education, 5: 61-78.

Klinger, C., \& Murray, N. 2012. Tensions in higher education: Widening participation, student diversity and the challenge of academic language/literacy. Widening Participation and Lifelong Learning, 14(1): 27-44.

Koch, A.J. 2013. The future of marketing education: A practitioner's perspective. Journal of Marketing Education, 34(1): 54-67.

Kolsaker, A. 2008. Academic professionalism in the managerialist era: a study of English universities. Studies in Higher Education, 33(5): 513-525.

Lawler, E. E., Hall, D. T., \& Oldham, G. R. 1974. Organizational climate: Relationship to organizational structure, process and performance. Organizational Behavior and Human Performance, 11(1): 139-155.

Lynch, K. 2015. Control by numbers: new managerialism and ranking in higher education. Critical Studies in Education, 56(2): 190-207. 
Lysons, A., \& Ryder, P. 1989. An application of Jones and James" perceived climate questionnaire in Australian higher educational institutions. Higher Education, 18: 697-705.

McGettigan, A. 2013. The Great University Gamble: Money, Markets and the Future of Higher Education. London: Pluto Press.

McKie, A. 2018. UK universities 'bleeding their business schools dry'. Times Higher Education Supplement 5 November 2018, https://www.timeshighereducation.com/news/ukuniversities-bleeding-their-business-schools-dry.

McMurray, A., \& Scott, D. 2003. Determinants of organisational climate for universities. Higher Education Research and Development, 32(6): 960-974.

Martin, B.R. 2016. What's happening to our universities? Prometheus, 34(1): 7-21.

Mellahi, K., \& Harris, L. 2016. Response rates in business and management research: An overview of current practice and suggestions for future direction. British Journal of Management, 27(2): 426-437.

Mertz, N., \& McNeely, S. 1990. How professors "learn" to teach: Teacher cognitions, teaching paradigms and teacher education. Paper presented at the annual meeting of the American Educational Research Association, Boston, MA, April 1990.

Molesworth, M., Nixon, E., \& Scullion, R. 2009. Having, being and higher education: the marketization of the university and the transformation of the student into consumer. Teaching in Higher Education, 14(3): 277-287.

Moran, E.T., \& Volkwein, J.F. 1988. Examining organisational climate in institutions of higher education. Research in Higher Education, 28(4): 367-383.

Moses, I., \& Ramsden, P. 1992. Academic values and academic practice in the new universities. Higher Education Research and Development, 11(2): 101-118.

Nixon, E., Scullion, R., \& Hearn, R. 2018. Her majesty the student: Marketized higher education and the narcissistic (dis)satisfaction of the student-consumer. Studies in Higher Education, 43(6): 927-943.

Noorda, S. 2013. Academic autonomy as a lifelong learning process for universities.

Leadership and Governance in Higher Education, 4. Available at: http://leadproject.org/sites/default/files/2017-04/Academic\%20Autonomy\%20for\%20universi.pdf [Accessed March 30, 2018].

Ostroff, C. 1993. The effects of climate and personal influences on individual behavior and attitudes in organizations. Organizational Behavior and Human Decision Processes, 56(1): 56-90.

Peterson, S.L., \& Wiesenberg, F. 2004. Professional fulfilment and satisfaction of US and Canadian adult education and human resource development faculty. International Journal of Lifelong Education, 23(2): 159-178. 
Poghosyan, L., Nannini, A., Stone, P.W., \& Smaldone, A. 2013. Nurse Practitioner organizational climate in primary care settings: Implications for professional practice. Journal of Professional Nursing, 29(6): 338-349.

Prosser, M., Trigwell, K., \& Taylor, P. 1994. A phenomenographic study of academics' conceptions of science learning and teaching. Learning and Instruction, 4(3): 217-231.

Ramsden, P. 2003. Learning to teach in higher education. London: Routledge.

Schibrowsky, J. A., Peltier, J. W., \& Boyt, T. E. 2002. A Professional School Approach to Marketing Education. Journal of Marketing Education, 24(1): 43-55.

Schneider, B. 1975. Organisational climate: An Essay. Personal Psychology, 28: 447-479.

Schneider, B., Ehrhart, M.G., \& Macey. W.H. 2013. Organisational climate and culture. Annual Review of Psychology, 64(1): 361-88.

Schneider, B., \& Rentsch, J. 1988. Managing climates and cultures: A futures perspective. In J. Hage (Ed.), Issues in organization and management series. Futures of organizations: Innovating to adapt strategy and human resources to rapid technological change (pp. 181203). Lexington, MA: Lexington Books.

Shaw, J. 2009. The diversity paradox: Does student diversity enhance or challenge excellence? Journal of Further and Higher Education, 32(4): 321-331.

Shulz, J. 2013. The impact of role conflict, role ambiguity, and organisational climate on the job satisfaction of academic staff in research-intensive universities in the UK. Higher Education Research and Development, 32(3): 464-478.

Stevenson, J., Burke., P.J., \& Whelan, P. 2014. Pedagogical stratification and the shifting landscape of higher education. York: The Higher Education Academy.

Stewart, D. W., \& Shamdasani, P. N. 2014. Focus Groups: Theory and Practice. 3rd edition. London: Sage.

Taberner, A.M. 2018. The marketization of the English higher education section and its impact on academic staff and the nature of their work, International Journal of Organisational Analysis, 26(1): 129-152.

Thompson, M.D. 2005. Organizational climate perception and job element satisfaction: A multi-frame application in a higher education setting. E-Journal of Organizational Learning and Leadership, 4(1). Available at: http://www.leadingtoday.org/weleadinlearning/mt05.htm [Accessed 8.05.2018].

Trede, F., Macklin, R. \& Bridges, D. 2012. Professional identity development: a review of the higher education literature. Studies in Higher Education, 37(3): 365-384.

Trigwell, K. \& Shale, S. 2004. Student learning and the scholarship of university teaching, Studies in Higher Education, 29(4): 523-536.

Volkwein, J.F., \& Zhou, Y. 2003. Testing a model of administrative job satisfaction. Research in Higher Education, 44(2): 149-171. 
Volkwein, J.F., Malik, S.M. \& Napierski-Prancl, M. 1998. Administrative satisfaction and the regulatory climate at public universities. Research in Higher Education, 39(1): 43-63.

Waring, M. 2014. Understanding Pedagogy. London: Routledge.

Wilensky, H.L. 1964. The Professionalization of Everyone? American Journal of Sociology, 70: 137-158.

\section{Appendix 1: Focus group discussion guide}

1. What do you see as the main challenges or changes affecting and shaping your role as a teacher in higher education?

2. What do you think accounts for these changes?

3. How have these challenges/changes affected your teaching practice?

4. How do you think that teaching in marketing is likely to evolve over the next few years and why?

Probes for discussion:

Opportunities for advancement; Students and stakeholders (professional associations, learned society, HEA, employers, government, society); Opportunities to develop your practice;

Working conditions; Resources; Management; Discipline content; External environment

\section{Appendix 2: Glossary of key acronyms.}

HEA - Higher Education Academy (now renamed Advance HE) is an organisation that works in partnership with universities to help the Academy collaborate, develop evidence-based practices and share teaching strategies and practice.

NSS - the UKs annual National Student Survey which assesses the views of final year undergraduates on their satisfaction with their degree course. It asks 27 questions about 8 
elements of the SE and one overall satisfaction question (the teaching on my course; learning opportunities; assessment and feedback; academic support; organisation and management; learning resources; learning community; student voice; overall satisfaction).

VL- Visiting Lecturer (or Part-Time staff) who are increasingly paid on an hourly basis for the input they make to teaching and represent a growing trend of precarity in university employment with no guarantees of ongoing employment. Using VL's allows managers to match supply and demand for courses over and above existing permanent employed Faculty.

REF- This is the government's competitive research funding exercise (The Research Excellence Framework) that seeks to assess the performance of individual Schools and Departments by subject area in terms of research income capture, quality of research outputs, numbers of completing doctoral students and other measures of research impact within society. 
Figure 1: Key themes and researchers in the literature on teaching practice
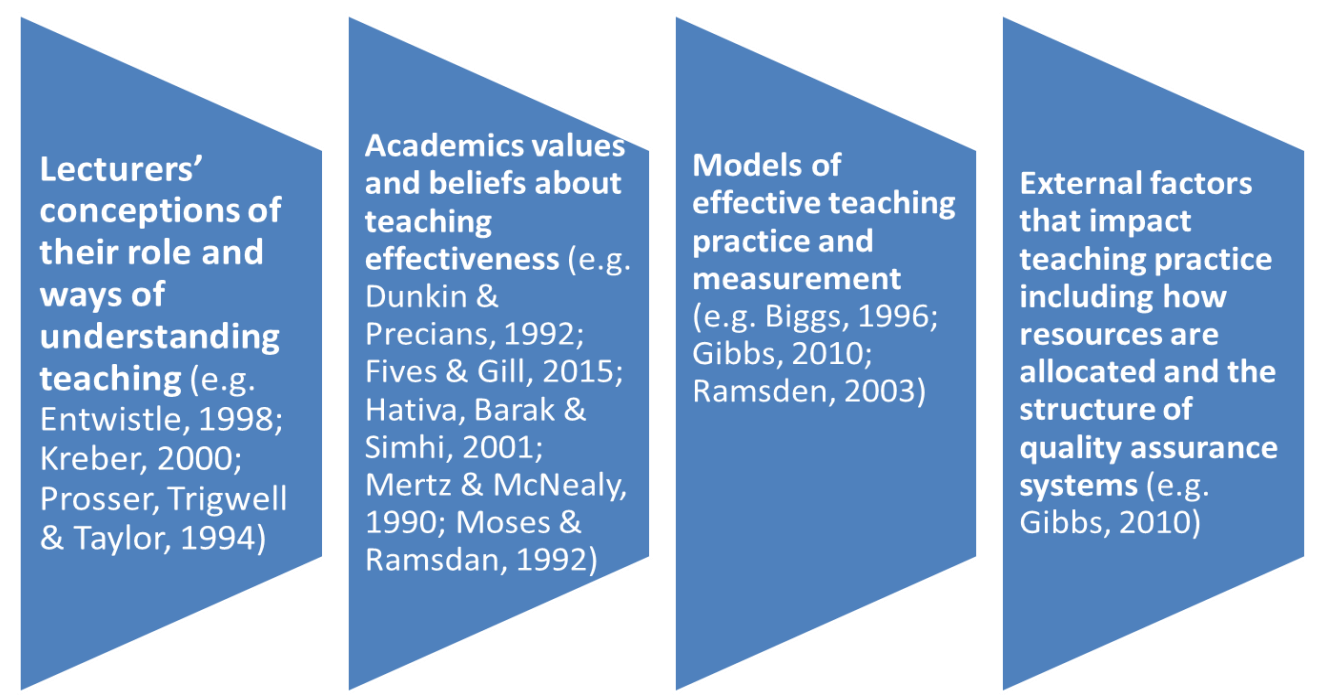

Figure 2: Main climate attributes found to shape university work and working relationships from eight key studies
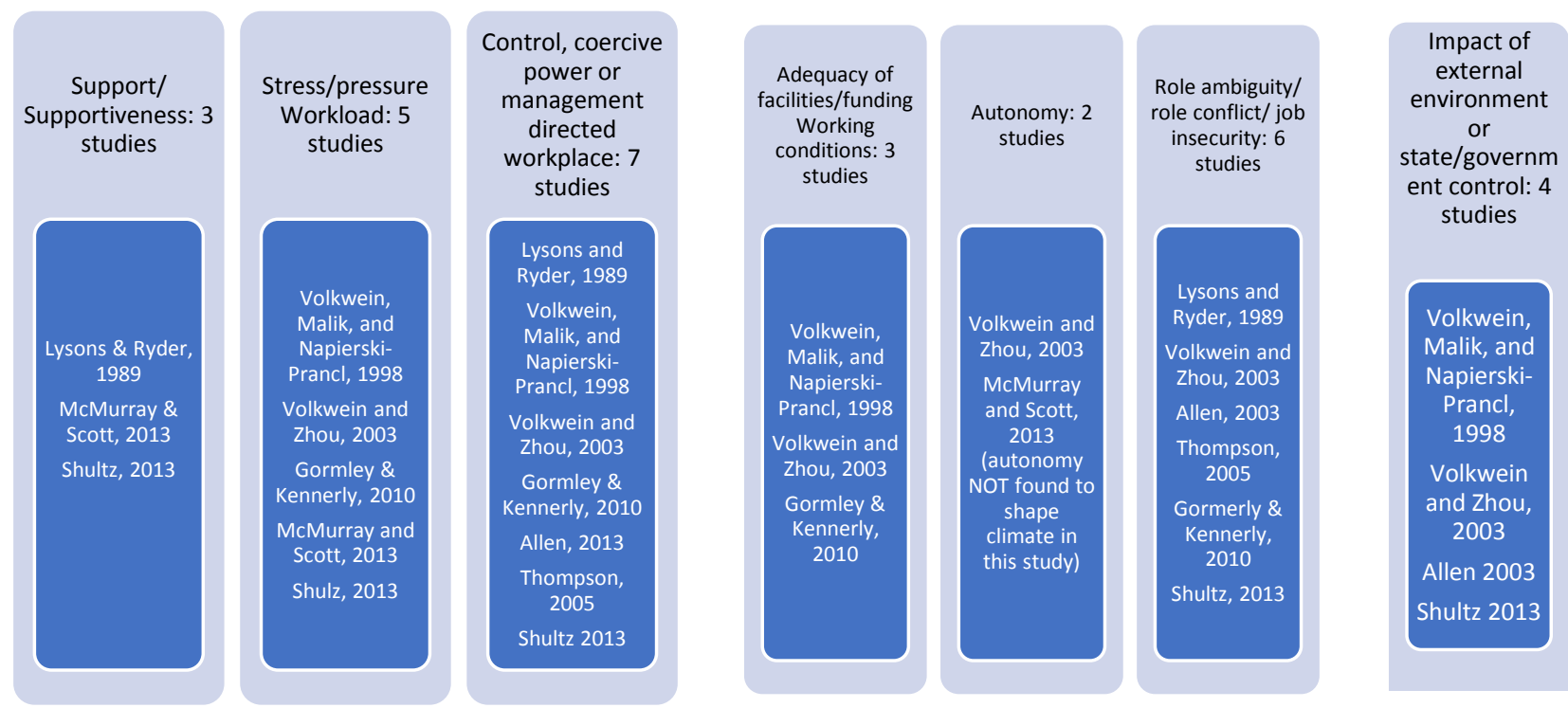
Figure 3: Conditions for teaching practice

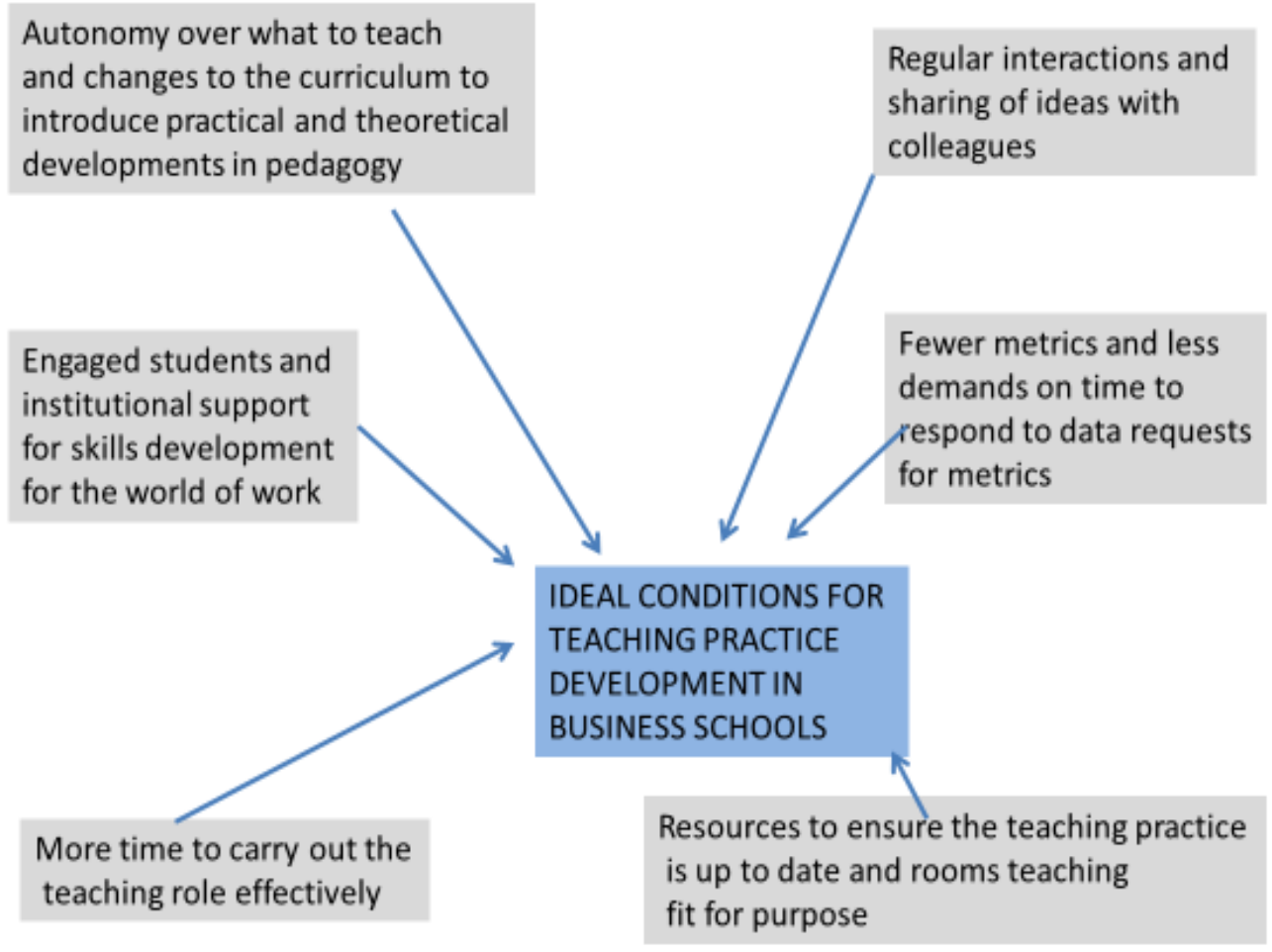




\section{TABLE 1}

Participants based on role, university type and years in service

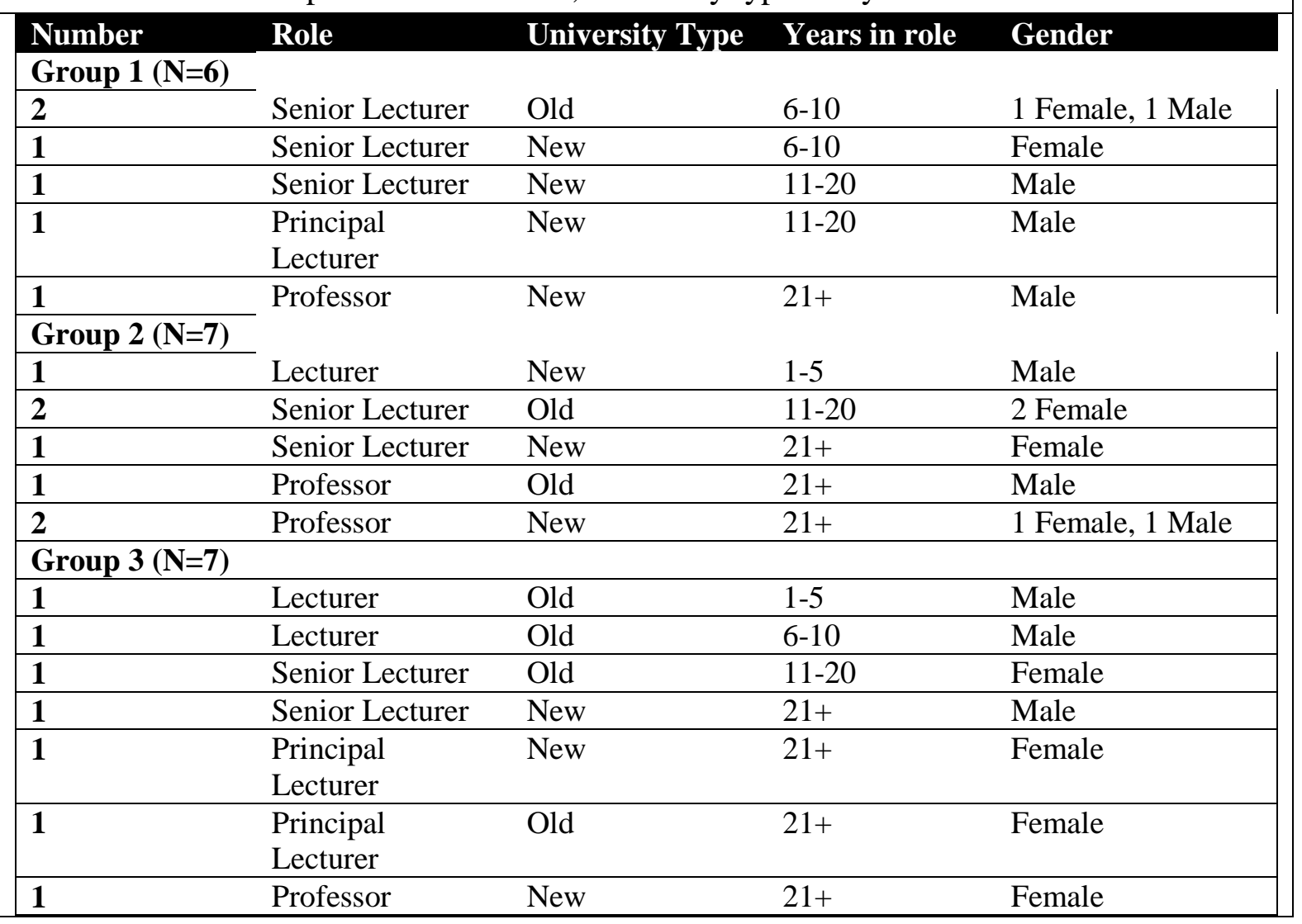

